\title{
Optimization and maximization of hexavalent molybdenum reduction to Mo-blue by Serratia sp. strain MIE2 using response surface methodology
}

\begin{abstract}
Molybdenum has long been known to be toxic to ruminants, but not to humans. However, more recently it has been increasingly reported that molybdenum shows toxic effects to reproductive organs of fish, mouse and even humans. Hence, its removal from the environment is highly sought after. In this study, response surface methodology (RSM) was successfully applied in the optimization and maximization of $\mathrm{Mo}^{6+}$ reduction to Mo-blue by Serratia sp. MIE2 for future bioremediation application. The optimal conditions predicted by RSM were $20 \mathrm{mM}$ molybdate, $3.95 \mathrm{mM}$ phosphate, $\mathrm{pH} 6.25$ and $25 \mathrm{~g} \mathrm{l}^{-1}$ sucrose with absorbance of 19.53 for Mo-blue production measured at $865 \mathrm{~nm}$. The validation experimental run of the predicted optimal conditions showed that the maximum Mo-blue production occurred at absorbance of 20.87 , with a $6.75 \%$ deviation from the predicted value obtained from RSM. Molybdate reduction was successfully maximized using RSM with molybdate reduction before and after optimization using RSM showing Mo-blue production starting at the absorbance value of 10.0 at $865 \mathrm{~nm}$ going up to an absorbance value above 20.87. The modelling kinetics of $\mathrm{Mo}^{6+}$ reduction showed that Teissier was the best model, with calculated $P_{\max }, K_{s}$ and $K_{i}$ values of 1.97 Mo-blue per hour, $5.79 \mathrm{mM}$ and $31.48 \mathrm{mM}$, respectively.
\end{abstract}

Keyword: Bioremediation; Response surface methodology; Hexavalent molybdenum; Modelling kinetics 